\title{
Commercial Sponges as A Novel Technology for Crude Oil Removal from Seawater and Industrial Wastewater: A Review
}

\author{
Maria - Anna Gatou ${ }^{1}$, Nefeli Lagopati ${ }^{1,2}$, Dimitrios Tsoukleris ${ }^{1}$ and Evangelia A. Pavlatou ${ }^{1 *}$ \\ ${ }^{1}$ Laboratory of General Chemistry, School of Chemical Engineering, National Technical University of Athens, Zografou Campus, Greece \\ ${ }^{2}$ Laboratory of Histology-Embryology, Molecular Carcinogenesis Group, Faculty of Medicine, School of Health Science, National and \\ Kapodistrian University of Athens, Greece
}

*Corresponding author: Evangelia A. Pavlatou, Laboratory of General Chemistry, School of Chemical Engineering, National Technical University of Athens, Zografou Campus, 9, Iroon Polytechniou str., 15780, Zografou, Athens, Greece

\begin{abstract}
ARTICLE INFO
Received: 幽 February 10, 2020

Published: 㸷 February 19, 2020

Citation: Maria Anna Gatou, Nefeli Lagopati, Dimitrios Tsoukleris, Evangelia Pavlatou. Commercial Sponges as A Novel Technology for Crude Oil Removal from Seawater and Industrial Wastewater: A Review. Biomed J Sci \& Tech Res 25(5)2020. BJSTR. MS.ID.004251.

Keywords: Commercial Sponges; Oil Absorption; Hydrophobic Modification; Crude Oil; Superoleophilicity

\section{ABSTRACT}

The global use of crude oil for energy applications has increased during the last decades, leading to an extensive release of oil into the environment as well. Thus, contamination deriving from oil spills and industrial wastewater has been recognized as one of the major environmental issues, imposing a serious threat to both human and marine ecosystem health. Treatment of contamination and pollution caused by crude oil constitutes a quite challenging and elaborate process. Among the conventional technologies applied for oil-water separation, oil absorption process has been widely examined in recent years. Commercial sponges, such as melamine and polyurethane sponges, have attracted great attention in the field of crude oil removal both from seawater and industrial wastewater, due to their low cost, high porous three-dimensional (3D) structure, low density, excellent mechanical properties and remarkable reusability. However, the amphipathic nature of commercial sponges limits their application for oil absorption treatment processes. In order to improve their oil absorption performance, several modification methods have been utilized. In the current manuscript, an overview of various methods used for the superhydrophobic/Superoleophilicity modification of commercially available sponges for oil-water separation, is provided, in order to highlight the potential use of these sponges as a novel, highly efficient, low-cost, recyclable and environmental friendly absorbent for the recovery of spilled crude oil both from seawater and industrial wastewater.
\end{abstract}

\section{Introduction}

Crude oil, originating from fossilized organic materials, constitutes a crucial financial resource for all the countries with established deposits [1,2]. In general, oil reserves are allocated on the shelves of the ocean, on the land, as well as in the inland seas. During extraction process, crude oil is tapped from the land or the bottom of the ocean and, then, its conveyance is conducted either through pipelines or with oil tankers to oil refineries for the production of diesel and other fuel oils, kerosene, ethane and several petrochemicals [1,2]. However, during the offshore exploitation and transportation processes, crude oil could be accidentally released into the ocean from the offshore platforms, drilling rigs, wells and tankers, leading to tremendous damage, as it not only directly affects the marine life, but also threatens human health, ecological balance and economy [3]. More specifically, due to its high viscosity, crude oil forms an impermeable layer on the water surface that affects marine flora and fauna, such as birds, mammals and bivalve mollusks, since it blocks the gas interchange and deflects the sun's rays, which are important to the photosynthesis process made by phytoplankton [4]. Other hazardous effects from oil contamination are the chemical toxicity from lighter chemical components, which are absorbed into organs, tissues and cells and can have sub-lethal or lethal toxic effects [5]. 
Actually, the polycyclic aromatic hydrocarbons in released crude oil can affect the cardiac function of fish [6], while crude oil and the chemical dispersant used in order to mitigate its impact have a negative effect on microzooplankton and may lead to the loss of key organisms with a specific function in an ecological community $[6,7]$. In some cases, the restoration of the ecosystem may take more than 10 years [8]. Furthermore, the economy of the wider area is affected too, since the fishing and tourism could be decreased severely [7,9]. Nowadays, oil pollution is considered a major environmental concern. It is estimated that the spilled oil volume reaches four billion tons per year globally [10]. Some of the most considerable oil spill examples worldwide are the Exxon Valdez oil spill in 1989, Prestige (Spain) in 2002, the storage tank explosion in Dalian (China) in 2010 and the Deepwater Horizon oil spill in the Gulf of Mexico in 2010 [11]. Apart from large-scale events, many smaller crude oil spills also threaten the aquatic environment, as they occur more frequently [12]. In the United States, for instance, approximately fifteen oil spill accidents occur daily in navigable waters $[10,13]$. However, seawater's oil contamination worldwide is also caused by the disposal of industrial wastewater containing crude oil residues to the sea. Thus, the development of novel and environmental-friendly materials for the effective removal of crude oil from polluted seawater and industrial wastewater is of crucial importance.

Currently, common oil removal techniques can be categorized into four different types $[10,14]$ :

(i) Mechanical recovery, such as booms, barriers, skimmers and absorbents [15],

(ii) In situ burning [16],

(iii) Chemical methods (dispersion, solidification) [17] and

(iv) Bioremediation [18] (Figure 1).

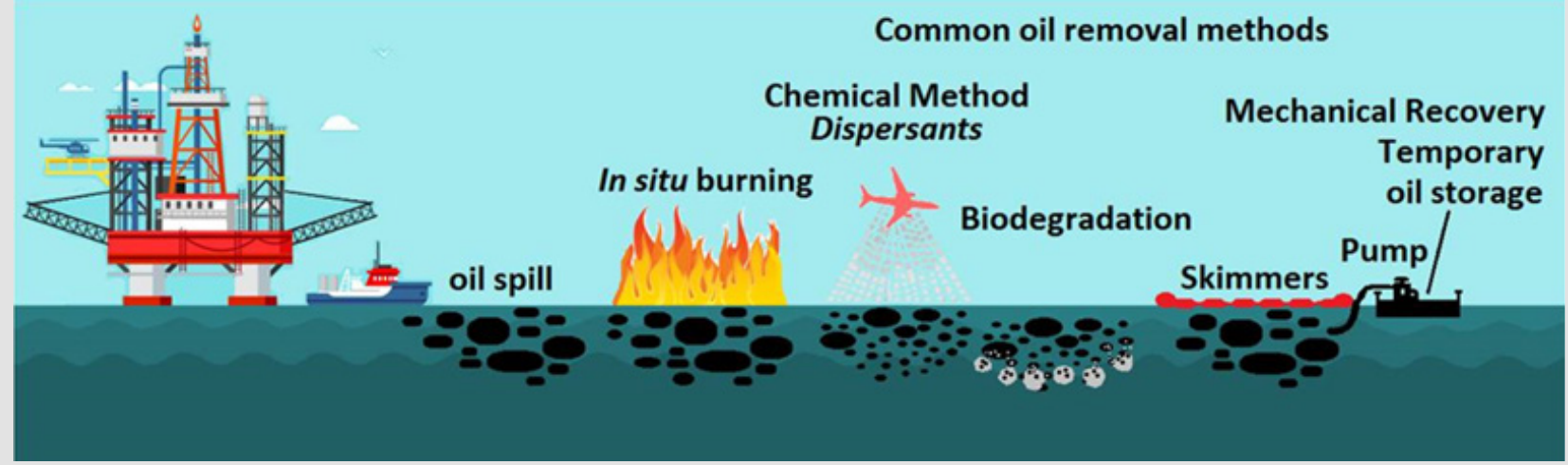

Figure 1: Common oil removal techniques.

The main benefits and drawbacks of each method are summarized in Table 1, so it is still a challenge to develop effective remediation solutions, in order to separate the spilled oil from the water without releasing residues into the environment $[10,13]$. In general, the separation of oil or water from oil/water mixtures can be divided into three main types: oil removal, water removal and controllable separation of oil or water [19]. Oil-removing materials should have the selectivity for absorbing or filtrating oil from oil/water mixtures [20]. Similarly, the water-removing materials can selectively filter or absorb water from an oil/water mixture [21]. The controllable separation material is a kind of switchable material, in which the oil removal or water removal depends on the $\mathrm{pH}$ variation and the magnetic or electrical control [22]. Among the types of oil/water separating materials, the oil removing type is the most attractive, due to its simple fabrication and easy operation [21]. There are various techniques that can induce surface roughness and enhance surface energy in between those of oil and water, in order to achieve superhydrophobicity and superoleophilicity [23]. Fabrication of oil filtrating and oil absorbent materials is considered as the primary strategy for the separation of oil from oil/water mixtures [24-26].

Table 1: The methods used for the removal of crude oil from water.

\begin{tabular}{|c|c|c|c|}
\hline Type of method & Technique & Benefits & Drawbacks \\
\hline $\begin{array}{l}\text { Mechanical } \\
\text { recovery }\end{array}$ & $\begin{array}{c}\text { Booms / barriers / } \\
\text { skimmers }\end{array}$ & $\begin{array}{c}\text { Low cost } \\
\text { Treatment of emulsified and viscous oils } \\
\text { No negative environmental effects }\end{array}$ & $\begin{array}{c}\text { Low selectivity } \\
\text { Low efficiency (rough weather, sea conditions) } \\
\text { Time consuming and expensive in a large scale } \\
\text { Demands large amount of personnel and } \\
\text { equipment }\end{array}$ \\
\hline
\end{tabular}




\begin{tabular}{|c|c|c|c|}
\hline & Absorption & $\begin{array}{c}\text { Low cost } \\
\text { Simple operation } \\
\text { High removal rate } \\
\text { Environmental friendly } \\
\text { Good recyclability }\end{array}$ & Difficult to be recovered \\
\hline In situ burning & & $\begin{array}{l}\text { Low cost } \\
\text { Removal of large oil quantities rapidly }\end{array}$ & $\begin{array}{l}\text { Minimum oil thickness 2-3 mm. } \\
\text { Affected by sea weather conditions } \\
\text { Production of harmful gases }\end{array}$ \\
\hline \multirow[t]{2}{*}{ Chemical } & Dispersants & $\begin{array}{c}\text { Elimination of a large oil volume rapidly and } \\
\text { effectively }\end{array}$ & $\begin{array}{l}\text { Secondary pollution (harmful to marine } \\
\text { ecosystem) } \\
\text { Effective for oils with viscosity <2000 cSt }\end{array}$ \\
\hline & Solidification & $\begin{array}{c}\text { Elimination of a large oil volume rapidly and } \\
\text { effectively }\end{array}$ & $\begin{array}{l}\text { Secondary pollution (harmful to marine } \\
\text { ecosystem) }\end{array}$ \\
\hline Bioremediation & Use of microorganisms & $\begin{array}{l}\text { Cost effective } \\
\text { Environmentally friendly }\end{array}$ & $\begin{array}{l}\text { Slow degradation rates } \\
\text { Low efficiency (ineffective in oil spills with large } \\
\text { coherent mass) } \\
\text { Limited to nutrient substrate, } \mathrm{pH} \text { and temperature }\end{array}$ \\
\hline
\end{tabular}

Absorption method has been regarded as one of the most effective technologies, as it is readily available, environmentally friendly, inexpensive and offers good recyclability [1,27,28]. A quite large number of traditional absorbent materials have been widely used, in order to remove oils from water, including wool, zeolites, activated carbon and so on [29]. However, traditional oilabsorbing materials are characterized by various disadvantages, such as poor absorption capacity, non-selective absorption and difficult reusability [30]. Therefore, novel alternative absorbents have been developed, such as textiles [31], membranes [32,33], meshes [34,35], foams [33,36], aerogels [37,38] and sponges [22,39]. Commercial sponges, including melamine sponges (MS) and polyurethane (PU) sponges have recently attracted great attention for oil/water separation processes and have been extensively studied and used, given their outstanding properties, such as their highly porous 3D structure, low bulk density, low cost, remarkable reusability, thermal stability and excellent mechanical properties $[40,41]$. Nevertheless, both polyurethane and melamine sponges are naturally amphipathic, which restricts the removal of oil from oil/water mixtures [39,42,43]. As a consequence, recent studies have focused on the surface modification of the two types of commercial sponges, in order to alter their surface from hydrophilic to hydrophobic for the sponges to have high oil absorption capacity and decent water repellency during the oil/water separation process [44]. Therefore, several materials have been used to switch the hydrophilic sponge surface to hydrophobic, such as silanes [45], hydrophobic polymers [46], hydrophobic nanoparticles [47,48], carbon materials [49-51] and various others, making commercial sponges promising candidates for crude oil removal both from seawater (oil spills) and industrial wastewater [52]. Lately, sponges with additional characteristics, such as magnetic properties, stimuli-responsiveness and high durability under harsh conditions, have also been developed in order to be used for the removal of crude oil in more distinct situations $[39,40]$. In this review, various techniques for the synthesis of novel superhydrophobic/ superoleophilic sponges are summarized, as they constitute a promising material for oil/water separation processes.

\section{Fabrication of Superhydrophobic/superhydrophobic Melamine Sponges}

Melamine sponges are open-cell foam structures, consisting of formaldehyde-melamine-sodium bisulfite copolymer that is used as an abrasive cleaner and as soundproofing material [53]. They are widely used for the fabrication of novel superhydrophobic materials for oil absorption applications. This type of sponge is very special because of owning privilege advantages, such as high porosity ( $>99 \%$ ), abundant pore canal, large surface area, low density (4-12 $\left.\mathrm{mg} / \mathrm{cm}^{3}\right)$, low cost, excellent elasticity, the ability of chemical modification and high thermal and mechanical stability [47,54-56]. As a result, based on the above unique properties, melamine sponges are being used for the fabrication of advanced crude oil absorption materials [57].

\section{Methods for Commercial Melamine Sponge Modification}

Commercial melamine sponges can be modified in order to acquire hydrophobicity through a variety of methods, including dip coating, chemical vapor deposition, in situ chemical reaction and carbonization [39].

Dip Coating: Dip coating constitutes the most frequently utilized method for the fabrication of hydrophobic/ superhydrophobic melamine sponges, as it is a simple technique that does not require sophisticated equipment and takes only a few hours for the desired sponge to be produced [57]. During the dip coating process, hydrophilic melamine sponges are immersed for a few times into a solution that contains surface-modifying agents, followed by a drying process, leading to the development of 
cs $[39,40]$ (Figure 2). In addition, the hydrophobicity of melamine sponges can be improved through pyrolysis at high temperature, which leads to the removal of their superficial hydrophilic groups $[54,58]$. Chen and his colleagues used the dip coating method for a simple, inexpensive and versatile fabrication of superhydrophobic and superoleophilic melamine sponge for oil absorption [59]. More specifically, they fabricated a polydimethylsiloxane (PDMS)functionalized melamine sponge, with absorption capacity of about 45-75 times its weight and good reusability through multiple oil absorption-squeezing cycles, making the as-prepared sponge a promising absorbent for large-scale cleanup of crude oil from seawater and industrial wastewater [59].

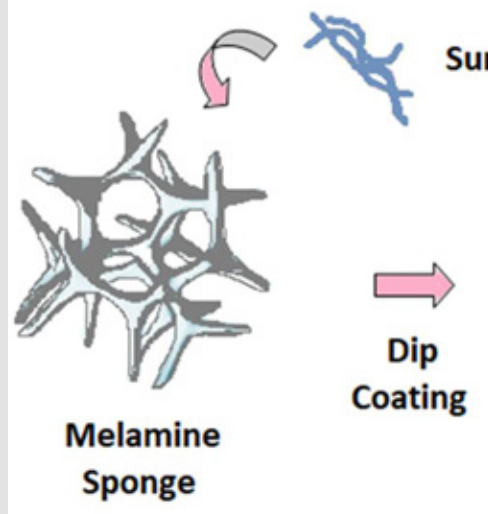

\section{Surfactant}

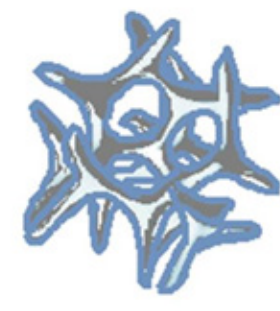

Modified Sponge

Figure 2: Modification of a melamine sponge via dip coating process.

In 2017, Lei and co-researchers fabricated a highly hydrophobic magnetic melamine sponge by dip coating of lignin [47]. The asacquired material with high porosity, excellent compressibility and light weight, could not only be controlled in order to absorb crude oil from water/wastewater through magnetic force, but also release the absorbed oil by the squeezing method or continuously collect it by the superhydrophobic sponges, through the assistance of constant-flow pumps [40,47,60]. Zhang et al., also utilized the dip coating method for the development of superoleophilic sponge for oil absorption by immersing commercial melamine sponge in ethanol solution that contained tannic acid (a typical plant polyphenol) and n-octadecyl amine $[14,43]$. The as-modified melamine sponge exhibited unique properties, such as superior absorption capacity up to 70-148 times of its own weight, high oil selectivity, robust mechanical stability after 1000 cycles, desirable recyclability through multiple absorption-extrusion cycles and superb flame retardation, making this sponge an excellent candidate for effective crude oil absorption and environmental remediation [14]. Furthermore, Li et al. utilized the dip coating method and reported a facile, cost-effective technology for the hydrophobic modification of melamine sponge using a water-based acrylic copolymer/silica hybrid superhydrophobic coating [41]. The asprepared superhydrophobic melamine sponge was characterized by excellent oil absorption capacity up to 78-172 times of its own weight and outstanding recyclability after 30 cycles of absorption-

squeezing-heating [41]. Finally, Lei et al. also employed the method of dip coating to fabricate a biomass-decorated carbonaceous melamine sponge with low cost, ultra-low density $\left(7,3 \mathrm{mg} / \mathrm{cm}^{3}\right)$, superhydrophobicity, high oil absorption capacity in a range of 86201 times of its weight and high oil retention, characteristics that make this type of modified melamine sponge a potential crude oil absorbent [54].

Chemical Vapor Deposition: Another method used for the hydrophilic to hydrophobic alteration of melamine sponges is chemical vapor deposition (CVD) [61]. Schematic representation of the CVD apparatus is shown in Figure 3. Compared to the dip coating method, CPD has the advantage of controlling the turbulent modification process, allowing the development of a dense and orderliness coating on the surface of the sponge [39]. This method leads to the production of materials of high purity and excellent performance and it has been widely used in the fabrication of hydrophobic sponges [39]. In 2017, Chen and co-workers modified chemically a melamine sponge by a simple vapor-phase deposition using polypyrrole (PPy) [62]. The obtained superhydrophobic sponge exhibited an efficient and fast oil/water separation performance and could be applied in industrial production due to its low cost and simple fabrication procedure [62].

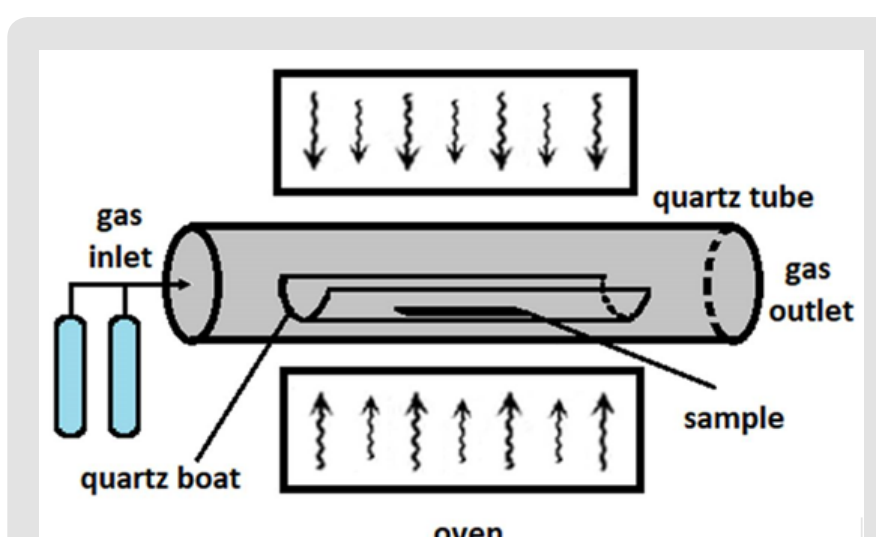

Figure 3: Schematic representation of the CVD apparatus.

In situ Chemical Reaction: Moreover, the in situ chemical reaction process, which includes wet chemical reaction, polymerization, thermal treatment and electroless deposition, constitutes another method used for the fabrication of superhydrophobic/superoleophilic melamine sponges [63]. Generally, in this process the commercial sponge with the 3D structure can act as a template, while the functional groups on the surface of the sponge suggest that it can serve as a reactant with potential modifications, in order to alter the sponge's surface from hydrophilic to hydrophobic $[39,64]$. During the wet chemical reaction, the sponge can function either as a carrier or a reactant to participate in the chemical modification process [39,65]. In 2018, Chung et al., fabricated a urea cross-link modified melamine sponge by a wet chemical reaction. The as-prepared sponge possessed superhydrophobicity, high oil absorption capacity (54-100 g/g) and outstanding oil selectivity [66]. 
In recent years, polymerization is also a frequently used method for the development of superhydrophobic sponges, where a polymer is cross-linked leading to the formation of polymeric chains that can act as a cross-link agent for connecting hydrophobic materials with the surface of the sponges (Figure 4) $[39,40]$. Conventionally, polymers characterized by low surface energy, such as polysiloxane, fluorine-containing polymers or long alkyl groups, are commonly used to coat the melamine sponge's surface via a cross-linking curing reaction, in situ polymerization or surface grafting $[54,67,68]$. Among various cross-link agents, dopamine constitutes the most widely used, as it can self-polymerize and result to the fabrication of stable covalent and non-covalent bonds between the materials [39] Wang J. et al., 2019. Based on this method, in 2017 Feng and coresearchers, modified commercial melamine sponge using furfuryl alcohol (FA) [68]. Furfuryl alcohol is capable of being mixed with water and a variety of organic solvents and polymerizes at elevated temperatures or under acidic conditions, producing hydrophobic poly (furfuryl alcohol) (PFA) [69]. The researchers reported that during the sponge's modification furfuryl alcohol polymerized onto the surface of the sponge and resulted to the fabrication of PFA-modified melamine sponge with excellent hydrophobicity, oil absorption capacity (75-160 g/g) and recycling abilities. Thus, such modified melamine sponge could be used as a highly efficient crude oil absorbent [68].

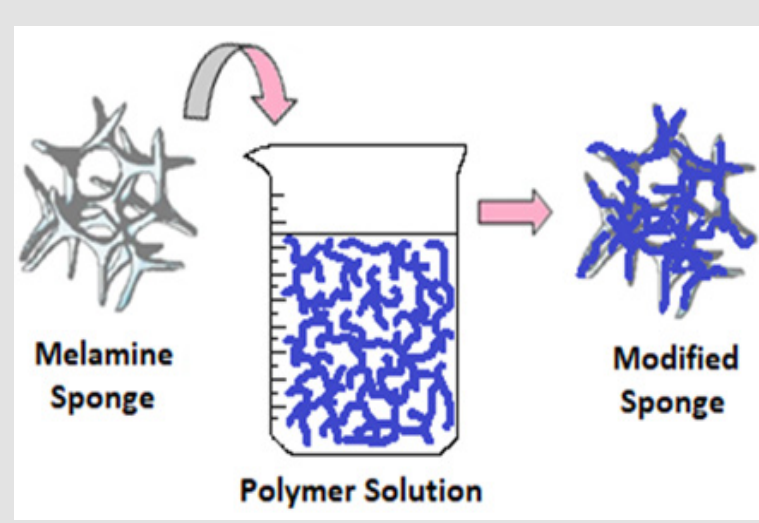

Figure 4: In situ polymerization of melamine sponges.

In addition, $\mathrm{Ge}$ and his scientific team reported the fabrication of a hierarchical-structured melamine sponge with superhydrophobicity and high oil capillarity, through the insitu polymerization of a novel phenolic resin (polybenzoxazine) [67]. Characterized by high porosity, excellent water repellence, enhanced oil capillarity and robust mechanical stability, the asprepared sponge exhibited a fast oil absorption speed, good recyclability and high absorption capacity [40]. Then, Lei and his colleagues fabricated a hydrophobic sponge by the immersion of a melamine sponge into dopamine solution until the formation of polydopamine (PDA) through polymerization [70]. The formation of PDA facilitated and ensured the strong attachment of zeolitic imidazolate framework-8 (ZIF-8) on the sponge's surface [71]. ZIF8 belongs to a sub-class of metal organic frameworks (MOFs) and it is characterized by high porosity, large surface area, low cost, exceptional chemical and thermal stability and special pore size $[72,73]$. The successful integration of both materials on the surface of the commercial melamine sponge, led to the development of a superhydrophobic sponge with excellent oil removal performance, as its mass-based oil absorption capacity varied between 1000 and $3800 \mathrm{wt} \%$ [58].

Another category of the in situ chemical reaction processes used for the fabrication of modified melamine sponges is thermal treatment [74]. This process constitutes a quiet "green" method, as no additional harmful reducing reagents are required and a cost-effective one, while it is commonly used for the fabrication of graphene modified sponges [39]. In 2015, Zhu et al. utilized the thermal treatment method, in order to produce a superoleophilic graphene modified melamine sponge [75]. More specifically, they reported a facile method to fabricate the graphene modified sponge through reduced graphene oxide ( $\mathrm{rGO}$ ) coated on melamine sponge by the thermal reduction of graphene oxide (GO) [75]. The asfabricated sponge was characterized by high performance, such as rough and superhydrophobic surface, high absorption capacity (up to 140 times its own weight), good recyclability (more than 50 cycles) and excellent oil/water separation efficiency (up to 99,98\%) for various oils [75]. Saha and Dashairya, fabricated a mechanically robust and macroporous rGO-modified melamine sponge by hydrothermal method [76]. The synthesized sponge exhibited superhydrophobicity/superoleophilicity, excellent oil absorption capacity up to 120 times of its weight, high oil selectivity and excellent recyclability, features that render the as-prepared modified melamine sponge a suitable absorbent for oil removal and recovery for seawater and wastewater treatment [77].

However, low temperature thermal treatment is also used for the fabrication of superhydrophobic melamine sponges. Qiu and co-researchers utilized this method in order to fabricate an rGOmodified melamine sponge [78]. In this case, the binding of rGO on the surface of the sponge was due to the chemical bonding generated during annealing $\left(\sim 200-300^{\circ} \mathrm{C}\right)$, rather than a simple physical coating, as it was utilized by Zhang and co-workers in their study [79]. As a result, the rGO-melamine sponge owned superhydrophobicity, excellent oil absorption performance over 50 cycles by squeezing and extremely high separation efficiency, up to $6 \times 10^{6} \mathrm{Lm}^{-3} \mathrm{~h}^{-1}$ in floating oil/water system [79]. Among the modification techniques mentioned so far, the in situ chemical reaction is characterized by more benefits regarding other conventional methods, such as chemical vapor deposition, as no specific equipment and conditions are required. Furthermore, compared to dip coating method, through the in situ chemical reaction can be formed stronger bonding forces between the materials acting as modifiers and the sponge surface [80]. Generally, the in situ chemical reaction method constitutes a facile, low cost and non-hazardous method for the fabrication of a superhydrophobic sponge with the desired characteristics [39]. 
Carbonization: Besides, carbonization is another convenient and efficient method suitable for the fabrication of modified melamine sponges with enhanced flame retardancy and improved properties in relation to the modified sponges utilizing the dip coating method [81]. Through carbonization are improved some crucial characteristics that a modified commercial sponge must possess, such as oil absorption capacity, chemical stability and temperature tolerance. In general, carbonized sponges are mainly prepared through mild carbonization at around $350-600^{\circ} \mathrm{C}$ of dip-coated sponges $[57,81]$ and few through carbonization at high temperatures $\left(\sim 1000^{\circ} \mathrm{C}\right)$ of raw sponges [81]. Compared to high-temperature carbonization, carbonization at moderate temperatures for the fabrication of carbonized sponges, can lead to the reduction of energy and equipment costs and also to the reduction of the risks of rigidifying and breaking the framework of products deriving either by excess carbonization or leakage oxidation [81,82]. In 2016, Yao and his team reported the fabrication of low-cost carbonized asphalt (DOA)-melamine sponge with high oil absorption capability, thermal stability and good recyclability, through the mild carbonization $\left(600^{\circ} \mathrm{C}\right)$ of the asphaltcoated sponge [81]. More specifically, the mild carbonization of DOA (deoiled asphalt), which was dip-coated onto the sponge's surface and contained abundant polycyclic aromatic hydrocarbons attached with various heteroatomic functional groups [83], had as a result its conversion into a graphene-rich film that provided melamine sponge with high hydrophobicity and excellent lipophilic wettability. Also, in 2016, Stolz et al. reported the elaboration of hydrophobic melamine-based sponges through a single-step carbonization (at $500-600^{\circ} \mathrm{C}$ ) of a commercial melamine sponge [84]. The obtained modified sponge exhibited excellent absorption capacities (90 to 200 times their own weight), a very high porosity of $99,5 \%$, a low density around $7 \mathrm{mg} / \mathrm{cm}^{3}$ and superhydrophobicity [84]. Zhao et al., finally, reported the green, inexpensive and convenient preparation of a highly oil-absorptive and water repellent sponge that derived from the carbonization of asphaltcoated melamine sponge at $500^{\circ} \mathrm{C}$ in pure nitrogen atmosphere [85]. The as-prepared sponge was characterized by highly selective absorption of oil against water, high oil absorption capacity (up to $246 \mathrm{~g} / \mathrm{g}$ ), good recyclability, flexible compressibility, fire resistance and low density [85]. Therefore, this type of modified melamine sponge can be a promising oil-absorbent material, suitable for several applications, such as oil pollution control from water of solid surface and oil-water separation [64].

In recent years, except for the methods, several other methods have also been used for the development of superhydrophobic melamine sponges. For example, Zhu et al. utilized a radical copolymerization process through which light-responsive Spiro pyran derivative was integrated with the melamine sponge (Zhu H. et al., 2015). The utilization of this process resulted to the fabrication of a light-responsive superhydrophobic melamine sponge with excellent oil selectivity and high absorption capacity from 70 to 154 times its own weight (Zhu H. et al., 2015). Most importantly, with the modification of light-responsive polymer, the sponge presented a conversion of superhydrophobic-hydrophilic performance under visible and UV irradiation thus the team developed a new responsive melamine sponge absorbent material and a new method for crude oil removal [86]. In 2017, Lei and co-researchers reported the fabrication of a temperature responsive melamine sponge with controllable wettability between superhydrophobicity and superhydrophilicity by grafting the octadecyl trichlorosilane and thermos-responsive polymer pNIPAAM (poly-N-isopropylacrylamide) onto the surface of melamine sponge [47]. The whole elaboration process included salinization and atom transfer radical polymerization. The as-obtained responsive material might be used for a low-cost, controllable and environmental-friendly oil-water separation [47]. Finally, in 2017 the same team [47] also fabricated a pH-responsive melamine sponge by grafting poly (4-vinylpyridine) on its surface through atom transfer radical polymerization. The obtained sponge showed excellent switchable wettability between superhydrophilicity and high hydrophobicity when contacting with different $\mathrm{pH}$ water droplets, presenting a good potential in controlled oil-water separation and oil recovery [47].

\section{Fabrication of Superhydrophobic/Superoleophilic Poly- urethane Sponges}

Every year more than $18 \times 10^{6}$ tons of polyurethane (PU) materials are produced; thus, the great production capacity makes them the sixth most used synthetic polymeric material worldwide [87]. Polyurethane sponge is a kind of porous (porosity typically $>95 \%$ ) polymer with the merits of low cost, high absorption ability, low density, good elasticity and easily scalable fabrication [88]. However, the polar groups such as carboxyl, as well as amino groups, present on their frameworks make these materials hydrophilic and reduce their selective nature and overall performance [77]. Hence, these materials obviously require a functional modification to display hydrophobicity for augmenting their absorption capacity [89]. In order to endow the polyurethane sponge with superhydrophobic properties, various nano-materials, such as $\mathrm{Fe}_{3} \mathrm{O}_{4}$ [90], $\mathrm{SiO}_{2}$ [91], $\mathrm{ZnO}$ [92], Ag [93], carbon nanotubes [94], graphene [95], have been used in order to develop a rough structure on the polyurethane sponge surface, which in combination with surface treatment by low surface energy materials that contain long chain hydrophobic groups [96-98], result to the elaboration of a superhydrophobic polyurethane sponge, suitable for oil-water separation.

\section{Methods for Polyurethane Sponge Modification}

In general, the synthetic methods reported in the literature for the fabrication of modified commercial polyurethane sponges are like those mentioned in the previous paragraph for the elaboration of modified melamine sponges [43]. The method of dip coating is the most widely used method for the fabrication of polyurethane sponges as well. Lü et al. reported the fabrication of a hydrophobic, 
flexible and microporous modified polyurethane sponge by coating silica nanoparticles-coated graphene oxide $\left(\mathrm{SiO}_{2} / \mathrm{GO}\right)$ nanohybrids on the sponge surface through a dip coating method [99]. The asprepared sponge exhibited hydrophobicity and high oil absorption capacity (up to 180 times its own weight). In 2018, Qiang and coworkers prepared a nanomaterial-functionalized sponge; they developed a functionalized nanoribbon/polyurethane sponge through a facile dip coating method [100]. The obtained modified sponge was characterized by superhydrophobicity, flexible elasticity, excellent electrical resistance, promising recyclability and durability (complete recovery after 100 cyclic compressions) and high absorption performance [100]. Also in 2018, Xia et al. utilized the dip coating method for the elaboration of a superhydrophobic reduced graphene oxide (rGO)-coated PU sponge, which exhibited high oil absorption capability, strong reusability, high oil-water separation efficiency ( 99\%) and fast absorption rate (the oil could be removed in $5 \mathrm{sec}$ ); these features render the as-prepared modified sponge a promising material for the removal of crude oil from seawater and industrial wastewater [95]. In the same year, Meng and co-researchers [101] also fabricated a superhydrophobic and superoleophilic functionalized PU sponge with good oil absorption capacity (up to 35 times of its own mass) and good reusability, using graphene oxide and dip coating. Moreover, Li et al. modified polyurethane sponges by coating their surface with magnetic $\mathrm{Fe}_{3} \mathrm{O}_{4}$ nanoparticles via a simple dip coating method [102]. The resultant $\mathrm{Fe}_{3} \mathrm{O}_{4} / \mathrm{PU}$ sponges possessed high water repellency and good oil affinity, as well as high oil absorption capability [102]. Baig and his colleagues, in 2019 also utilized the dip coating technique, in order to load PU sponge with carbon nanofibers (CNF) [103].

Namely, the CNF loading led to high hydrophobicity, mechanical stability, high oil absorption capacity, chemical inertness, large surface area and small pore size) [103]. Finally, Yu et al. fabricated a magnetic superhydrophobic/superoleophilic polyurethane sponge with good oil absorption capacity through the addition of pre-synthesized $\mathrm{Fe}_{3} \mathrm{O}_{4}$ nanoparticles and upon immersion in highdensity polyethylene (HDPE) [104]. The simplicity of its fabrication method, together with its outstanding stability, cyclic lifetime and separation capacity makes it of interest for crude oil removal applications [104]. In 2015, Wu et al. fabricated a magnetic, durable and superhydrophobic $\mathrm{Fe}_{3} \mathrm{O}_{4} / \mathrm{SiO}_{2} / \mathrm{PU}$ sponge by chemical vapor deposition [105]. The as-modified sponge exhibited fast magnetic responsivity, excellent superhydrophobicity/superoleophilicity, high efficiency in oil-water separation, excellent mechanical stability, oil stability and reusability in terms of superhydrophobicity and oil absorbents; thus this material is very promising for practical oil absorption and oil-water separation [105]. Additionally, Rahmani et al. utilized the CVD method for the preparation of nano porous graphene (NPG), which was then integrated with the porous texture of PU, leading to an NPG/PU sponge [106]. The modified sponge showed hydrophobic and oleophilic characteristics, high oil selectivity, as well as oil absorption capacity and excellent recyclability [106].
Polymerization constitutes also a commonly used method for the fabrication of superhydrophobic polyurethane sponges in recent years [107]. Wang et al., inspired by the remarkable adhesive ability of dopamine, presented a feasible approach to fabricate carbon nanotubes (CNTs)-reinforced polyurethane sponge with superhydrophobicand superoleophilicproperties [108]. Themethod they utilized involved the oxidative self-polymerization of dopamine, while the as-obtained sponge exhibited outstanding features, such as water repellency, superhydrophobic stability over temperature and corrosion, high mechanical strength, excellent elasticity, high selective absorption capacity up to 34,9 times of its own weight and, lastly, excellent recyclability [108]. Based on polymerization as well, Shuai et al. developed a novel poly(dimethylsiloxane)$\mathrm{TiO}_{2}$ modified PU sponge with superhydrophobic properties. In particular, the sponge was facilely fabricated by sol-gel growth of $\mathrm{TiO}_{2}$ nanoparticles on the surface of the sponge, followed by in situ polymerization of poly(dimethylsiloxane) (PDMS) [88]. The modified polyurethane sponge presented high absorption capacity to a variety of oils, excellent absorption selectivity to diesel oil in diesel oil-water mixture and outstanding recyclability [109]. As a result, the excellent absorption performance coupled with the simple preparation process of the as-modified sponge indicates its great application potential, both in the oil spill cleanup and oil removal from industrial wastewater [110]. In 2019, Liu and his coresearchers fabricated a superhydrophobic PU sponge by a simple dopamine polymerization and surface treatment with hexamethyl disilazane (HMDS) [96]. The elaborated sponge exhibited superhydrophobicity and porous structure, as well as high oil absorption capacity and stable recycling performance in oil-water separation) [96]. Meanwhile, the sponge possessed excellent compressibility and good recovery ability under compression test) [96].

Zhou et al. utilized another technique for the fabrication of superhydrophobically modified polyurethane sponges. More specifically, they developed a graphene-modified polyurethane sponge by solvothermal technique [111]. The sponge possessed superhydrophobicity and high oil-water separation efficiency $(>99,5 \%$ ) [111]. Li et al. successfully fabricated a superhydrophobic 3D rambutan-like- $\beta$ - $\mathrm{NiOOH}$ polyurethane sponge through a lowtemperature hydrothermal method [112]. The sponge exhibited good mechanical stability, heat stability, anti-acid corrosion ability, as well as good abilities for selective oil absorption, high oil absorption capacity and recycling ability [112]. In 2018, Zhao et al. developed a graphene-polyurethane sponge using low-value petroleum asphaltene via a facile and inexpensive carbonization technique [113]. The modified sponge presented high hydrophobic and superoleophilic properties, in combination with excellent oil absorption performance; thus, the sponge constitutes a promising material for the pollution control of spilt oil in seawater and removal of oil from industrial wastewater [113]. Besides the methods mentioned above, other methods have also been reported in the literature for the fabrication of superhydrophobic polyurethane 
sponges $[107,114]$. Tran and Lee laden zinc oxide (ZnO) flakes on the PU sponge surface via a rapid microwave method [114]. After a facile $\mathrm{ZnO}$-coating step performed with a commercial microwave, the hydrophilic sponge's surface turned to superhydrophobic, resulting to a modified sponge with high oil-water separation efficiency (>99\%) and oil absorption capacity [114]. Finally, Zhao et al. [115] designed an in situ self-assembly method to fabricate a kind of hydrophobic and oleophilic MOF-coated PU sponge [115]. The as-obtained sponge exhibited superior absorption capacity (around 33 times of its own weight), recyclability and flame retardancy.

\section{Conclusion}

Commercial sponge materials, such as melamine and polyurethane sponges, have been widely explored to be utilized as crude oil absorbents. However, these sponges are naturally amphipathic, which means that they absorb water and oil simultaneously. In order to remove crude oil from seawater and industrial wastewater, the modified sponges must possess hydrophobic and oleophilic properties. Taking this into consideration, a wide variety of methods and materials have been used for the elaboration of the desired hydrophobic sponges. In this review are presented various modification methods that have been applied to modify commercial sponges in recent years. These methods not only have remarkably simplified the process of sponges' surface modification but have significantly enhanced their absorption capacity and reduced the fabrication cost as well.

Despite the fact that numerous sponge-based absorbents have been successfully fabricated, several issues need further investigation prior to the utilization of these sponges in crude oil removal, such as the use of superhydrophobic/superoleophilic sponges in real crude oil removal applications, their use as absorbents of high-viscosity oils, the effect of several parameters (like $\mathrm{pH}$ and temperature) in the sponges' performance and, lastly, the recycling-retrieval of the used sponges that have reached their potential oil absorption capacity after given cycles of reuse.

\section{Acknowledgment}

This research is implemented through IKY scholarships program and co-financed by the European Union (European Social Fund - ESF) and Greek national funds through the action entitled "Reinforcement of Postdoctoral Researchers", in the framework of the Operational Program "Human Resources Development Program, Education and Lifelong Learning" of the National Strategic Reference Framework (NSRF) 2014 - 2020 - MIS5001552.

\section{Conflict of Interest}

The authors declare no conflict of interest.

\section{References}

1. Zhang T, Li ZD, Lü YF, Liu Y, Yang DY, et al. (2019) Recent progress and future prospects of oil-absorbing materials. Chinese Journal of Chemical Engineering 27(6): 1282-1295.
2. Kostianoy A, Lavrova O (2014) Introduction. In Oil Pollution in the Baltic Sea. The Handbook of Environmental Chemistry. Springer-Verlag Berlin Heidelberg.

3. Korotenko KA (2018) Effects of mesoscale eddies on behavior of an oil spill resulting from an accidental deepwater blowout in the Black Sea: an assessment of the environmental impacts. PeerJ 6: e5448.

4. Rogowska J, Namieśnik J (2010) Environmental implications of oil spills from shipping accidents. Rev Environ Contam Toxicol 206: 95-114.

5. Odukoya J, Lambert R, Sakrabani R (2019) Understanding the Impacts of Crude Oil and its Induced Abiotic Stresses on Agrifood Production: A Review. Horticulturae (Basel, Switzerland) 5(2): 47.

6. Yin Z, Li Y, Song T, Bao M, Li Y, et al. (2020) An environmentally benign approach to prepare superhydrophobic magnetic melamine sponge for effective oil/water separation. Separation and Purification Technology 236.

7. Tapia J, Alvarado-Gómez E, Encinas A (2019) Non-expensive hydrophobic and magnetic melamine sponges for the removal of hydrocarbons and oils from water. Separation and Purification Technology 222: 221-229.

8. Gann GD, Mc Donald T, Walder B, Aronson J, Nelson CR, et al. (2019) International principles and standards for the practice of ecological restoration. (2 ${ }^{\text {nd }}$ Edn.). Restoration Ecoology 27: S1-S46.

9. Zhang B, Matchinski EJ, Chen B, Ye X, Jing L, et al. (2019) Chapter 21 marine oil spills - oil pollution, sources and effects. In World Seas: An Environmental Evaluation, Academic Press pp. 391-406.

10. Qiao K, Tian W, Bai J, Wang L, Zhao J, et al. (2019) Application of magnetic adsorbents based on iron oxide nanoparticles for oil spill remediation: A review. Journal of the Taiwan Institute of Chemical Engineers 97: 227236.

11. Xiong S, Long H, Tang G, Wan J, Li H (2015) The management in response to marine oil spill from ships in China: A systematic review. Marine Pollution Bulletin 96(1-2): 7-17.

12. Zabbey N, Olsson G (2017) Conflicts - Oil Exploration and Water. Global challenges $1(5)$.

13. Pinto J, Athanassiou A, Fragouli D (2018) Surface modification of polymeric foams for oil spills remediation. Journal of Environmental Management 206: 872-889.

14. Zhang L, Dong D, Shao L, Xia Y, Zeng T, et al. (2019) Cost-effective one-pot surface modified method to engineer a green superhydrophobic sponge for efficient oil/water mixtures as well as emulsions separation. Colloids and Surfaces A: Physicochemical and Engineering Aspects 576: 43-54.

15. Li J, Yan L, Tang X, Feng H, Hu D, et al. (2016) Robust superhydrophobic fabric bag filled with polyurethane sponges used for vacuum-assisted continuous and ultrafast absorption and collection of oils from water. Advanced Materials Interfaces 3(9).

16. Ossai IC, Ahmed A, Hassan A, Hamid FS (2020) Remediation of soil and water contaminated with petroleum hydrocarbon: A review. Environmental Technology \& Innovation 17.

17. Hohl L, Knossalla M, Kraume M (2017) Influence of dispersion conditions on phase separation in liquid multiphase systems. Chemical Engineering Science 171(2): 76-87.

18. Imam A, Suman SK, Ghosh D, Kanaujia PK (2019) Analytical approaches used in monitoring the bioremediation of hydrocarbons in petroleumcontaminated soil and sludge. TrAC Trends in Analytical Chemistry 118: $50-64$.

19. Xu S, Sheng R, Cao Y, Yan J (2019) Reversibly switching water droplets wettability on hierarchical structured $\mathrm{Cu}_{2} \mathrm{~S}$ mesh for efficient oil/water separation. Scientific reports 9(1): 12486.

20. Abdulhussein AT, Kannarpady GK, Biris AS (2019) One-step synthesis of a steel-polymer wool for oil-water separation and absorption. npj Clean Water 2: 10 .

21. Yong J, Huo J, Chen F, Yang Q, Hou X (2018) Oil/water separation based 
on natural materials with super-wettability: recent advances. Phys. Chem. Chem. Phys 20: 25140-25163.

22. Phanthong P, Reubroycharoen P, Kongparakul S, Samart C, Wang Z, et al. (2018) Fabrication and evaluation of nanocellulose sponge for oil/water separation. Carbohydrate Polymers 190: 184-189.

23. Avrămescu RE, Ghica MV, Dinu Pîrvu C, Prisada R, Popa L (2018) Superhydrophobic Natural and Artificial Surfaces-A Structural Approach. Materials (Basel, Switzerland) 11(5): 866.

24. Liu H, Geng B, Chen Y, Wang H (2017) Review on the aerogel-type oil sorbents derived from nanocellulose. ACS Sustainable Chemistry \& Engineering 5(1): 49-66.

25. Lu Y, Wang Y, Liu L, Yuan W (2017) Environmental-friendly and magnetic/silanized ethyl cellulose sponges as effective and recyclable oil-absorption materials. Carbohydrate Polymers 173: 422-430.

26. Xiao C, Si L, Liu Y, Guan G, Wu D, et al. (2016) Ultrastable coaxial cablelike superhydrophobic mesh with self-adaption effect: facile synthesis and oil/water separation application. Journal of Materials Chemistry A 4(21): 8080-8090.

27. Sharma VK, Yang X, Cizmas L, McDonald TJ, Luque R, et al. (2017) Impact of metal ions, metal oxides and nanoparticles on the formation of disinfection byproducts during chlorination. Chemical Engineering Journal 317: 777-792.

28. Zhang C, Yang D, Zhang T, Qiu F, Dai Y, et al. (2017) Synthesis of $\mathrm{MnO}_{2}$ / poly(n -butylacrylate- co-butyl methacrylate-co-methyl methacrylate) hybrid resins for efficient oils and organic solvents absorption. Journal of Cleaner Production 148: 398-406.

29. Crini G, Lichtfouse E, Wilson L, Morin-Crini N (2018) Adsorptionoriented processes using conventional and non-conventional adsorbents for wastewater treatment. In Green Adsorbents for Pollutant Removal, Environmental Chemistry for a Sustainable World, 18, Springer 18: 23 71.

30. Liu P, Zhang Y, Liu S, Zhang Y, Du Z, et al. (2019) Bio-inspired fabrication of fire-retarding, magnetic-responsive, superhydrophobic sponges for oil and organics collection. Applied Clay Science 172: 19-27.

31. Yang M, Liu W, Jiang C, Xie Y, Shi H, et al. (2019) Facile construction of robust superhydrophobic cotton textiles for effective UV protection, self-cleaning and oil-water separation. Colloids and Surfaces A: Physicochemical and Engineering Aspects 570: 172-181.

32. Yue X, Li Z, Zhang T, Yang D, Qiu F (2019) Design and fabrication of superwetting fiber-based membranes for oil/water separation applications. Chemical Engineering Journal 364: 292-309.

33. Zhang J, Chen R, Liu J, Liu Q, Yu J, et al. (2019) Construction of ZnO@ $\mathrm{Co}_{3} \mathrm{O}_{4}$-loaded nickel foam with abrasion resistance and chemical stability for oil/water separation. Surface and Coatings Technology 357: 244-251.

34. Khosravi M, Azizian S, Boukherroub R (2019) Efficient oil/water separation by superhydrophobic $\mathrm{Cu} S$ coated on copper mesh Separation and Purification Technology 215: 573-581.

35. Xie A, Cui J, Chen Y, Lang J, Li C, et al. (2019) Capillarity-driven both light and heavy oil/water separation via combined system of opposite superwetting meshes. Separation and Purification Technology, 215: 1-9.

36. Du J, Zhang C, Pu H, Li Y, Jin S, et al. (2019) HKUST-1 MOFs decorated 3D copper foam with superhydrophobicity/superoleophilicity for durable oil/water separation. Colloids and Surfaces A 573: 222-229.

37. Li Z, Zhong L, Zhang T, Qiu F, Yue X, et al. (2019) Sustainable, flexible and superhydrophobic functionalized cellulose aerogel for selective and versatile oil/water separation. ACS Sustainable Chemistry \& Engineering 7(11): 9984-9994.

38. Zhang YG, Zhu YJ, Xiong ZC, Wu J, Chen F (2018) Bioinspired ultralight inorganic aerogel for highly efficient air filtration and oil-water separation. ACS Applied Materials and Interfaces 10(15): 13019-13027.
39. Peng M, Zhu Y, Li H, He K, Zeng G, et al. (2019) Synthesis and application of modified commercial sponges for oil-water separation. Chemical Engineering Journal 373: 213-226.

40.Guan Y, Cheng F, Pan Z (2019) Superwetting Polymeric Three Dimensional (3D) Porous Materials for Oil/Water Separation: A Review. Polymers 11(5): 806.

41. Li M, Bian C, Yang G, Qiang X (2019) Facile fabrication of water-based and non-fluorinated superhydrophobic sponge for efficient separation of immiscible oil/water mixture and water-in-oil emulsion. Chemical Engineering Journal 368: 350-358.

42. Zhang W, Zhai X, Xiang T, Zhou M, Zang D, et al. (2017) Superhydrophobic melamine sponge with excellent surface selectivity and fire retardancy for oil absorption. Journal of Materials Science 52(1): 73-85.

43. Peng J, Deng J, Quan Y, Yu C, Wang H, et al. (2018) Superhydrophobic Melamine Sponge Coated with Striped Polydimethylsiloxane by ThiolEne Click Reaction for Efficient Oil/Water Separation. ACS omega 3(5): 5222-5228.

44. Minju N, Ananthakumar S, Savithri S (2019) Superswelling Hybrid Sponge from Water Glass for Selective Absorption of Crude Oil and Organic Solvents. ACS omega 4(19): 17990-18001.

45. Tian Q, Liu Q Zhou J, Ju P, Waterhouse, et al. (2019) Superhydrophobic sponge containing silicone oil-modified layered double hydroxide sheets for rapid oil-water separations. Colloids and Surfaces A: Physicochemical and Engineering Aspects 570: 339-346.

46. Afolabi RO, Oluyemi GF, Officer S, Ugwu JO (2019) Hydrophobically associating polymers for enhanced oil recovery - Part A: A review on the effects of some key reservoir conditions. Journal of Petroleum Science and Engineering 180: 681-698.

47. Lei Z, Zhang G, Ouyang Y, Liang Y, Deng Y, et al. (2017) Simple fabrication of multi-functional melamine sponges. Materials Letters 190: 119-122.

48. Cho EC, Chang Jian CW, Hsiao YS, Lee KC, Huang JH (2016) Interfacial engineering of melamine sponges using hydrophobic $\mathrm{TiO}_{2}$ nanoparticles for effective oil/water separation. Journal of the Taiwan Institute of Chemical Engineers 67: 476-483.

49. He K, Chen G, Zeng G, Chen A, Huang Z, et al. (2018) Three-dimensional graphene supported catalysts for organic dyes degradation. Applied Catalysis B: Environmental 228: 19-28.

50. Shiu RF, Lee CL, Hsieh PY, Chen CS, Kang YY, et al.(2018) Superhydrophobic graphene-based sponge as a novel sorbent for crude oil removal under various environmental conditions. Chemosphere 207: 110-117.

51. Bagoole O, Rahman MM, Shah S, Hong H, Chen H, et al. (2018) Functionalized three-dimensional graphene sponges for highly efficient crude and diesel oil adsorption. Environmental Science and Pollution Research 25(23): 23091-23105.

52. Jmaa SB, Kallel A (2019) Assessment of Performance of Posidona oceanica (L.) as Biosorbent for Crude Oil-Spill Cleanup in Seawater BioMed Research International 2019.

53. Pham VH, Dickerson JH (2014) Superhydrophobic silanized melamine sponges as high efficiency oil absorbent materials. ACS Applied Materials \& Interfaces 6(16): 14181-14188.

54. Lei Z, Zheng P, Niu L, Yang Y, Shen J, et al. (2019) Ultralight, robustly compressible and superhydrophobic biomass-decorated carbonaceous melamine sponge for oil/water separation with high oil retention. Applied Surface Science 489: 922-929.

55. Sun S, Tang S, Chang X, Wang N, Wang D, et al. (2019) A bifunctional melamine sponge decorated with silver-reduced graphene oxide nanocomposite for oil-water separation and antibacterial applications. Applied Surface Science 473: 1049-1061.

56. Demirel G, Aygül E (2019) Robust and flexible superhydrophobic/ superoleophilic melamine sponges for oil-water separation. Colloids and Surfaces A: Physicochemical and Engineering Aspects 577: 613-621. 
57. Zhou Y, Wang Y, Liu T, Xu G, Chen G, et al. (2017) Superhydrophobic hBNRegulated Sponges with Excellent Absorbency Fabricated Using a Green and Facile Method. Scientific reports 7.

58. Zhang Y, Zhang Q Zhang R, Liu S, Zhou Y (2019) A superhydrophobic and elastic melamine sponge for oil/water separation. New Journal of Chemistry 43: 6343-6349.

59. Chen X, Weibel JA, Garimella SV (2016) Continuous oil-water separation using polydimethylsiloxane-functionalized melamine sponge. Industrial and Engineering Chemistry Research 55(12): 3596-3602.

60. Jiang ZR, Ge J, Zhou YX, Wang ZU, Chen D, et al. (2016) Coating sponge with a hydrophobic porous coordination polymer containing a lowenergy CF3-decorated surface for continuous pumping recovery of an oil spill from water. NPG Asia Materials 8(3): 253-253.

61. Kim D, Im H, Kwak MJ, Byun E, Im SG (2016) A Superamphiphobic Sponge with Mechanical Durability and a Self-Cleaning Effect. Scientific reports 6: 29993

62. Chen J, You H, Xu L, Li T, Jiang X, et al. (2017) Facile synthesis of a two-tier hierarchical structured superhydrophobic-superoleophilic melamine sponge for rapid and efficient oil/water separation. Journal of Colloid and Interface Science 506: 659-668.

63. Wang Z, Yang HC, He F, Peng S, Li Y, et al. (2019) Mussel-Inspired Surface Engineering for Water-Remediation Materials. Matter 1(1): 115-155.

64. Chen J, Xiang J, Yue X, Li H, Yu X (2019) Synthesis of a Superhydrophobic Polyvinyl Alcohol Sponge Using Water as the Only Solvent for Continuous Oil-Water Separation. Composite/Hybrid Materials for Wastewater Treatments.

65. Oribayo O, Pan Q Feng X, Rempel GL (2017) Hydrophobic surface modification of FMSS and its application as effective sorbents for oil spill clean-ups and recovery. AIChE Journal 63(9): 4090-4102.

66. Chung CH, Liu WC, Hong JL (2018) Superhydrophobic melamine sponge modified by cross-linked urea network as recyclable oil absorbent materials. Industrial and Engineering Chemistry Research 57(25): 8449-8459.

67. Ge J, Wang F, Yin X, Yu J, Ding B (2018) Polybenzoxazine functionalized melamine sponges with enhanced selective capillarity for efficient oil spill cleanup. ACS Applied Materials \& Interfaces 10(46): 40274-40285.

68. Feng Y, Wang Y, Wang Y, Yao J (2017) Furfuryl alcohol modified melamine sponge for highly efficient oil spill clean-up and recovery. Journal of Material Chemistry A 5(41): 21893-21897.

69. Moazzen K, Zohuriaan Mehr MJ, Jahanmardi R, Kabiri K (2017) Toward poly (furfuryl alcohol) applications diversification: Novel self-healing network and toughening epoxy-novolac resin. Journal of Applied Polymer Science 135(12).

70. Lei Z, Deng Y, Wang C (2018) Multiphase surface growth of hydrophobic ZIF-8 on melamine sponge for excellent oil/water separation and effective catalysis in a Knoevenagel reaction. Journal of Materials Chemistry A 6(7): 3258-3263.

71. Fu F, Zheng B, Xie LH, Du H, Du S, et al. (2018) Size-Controllable Synthesis of Zeolitic Imidazolate Framework/Carbon Nanotube Composites. Crystals (Basel, Switzerland) 8(10): 367.

72. Oozeerally R, Ramkhelawan SDK, Burnett DL, Tempelman CHL, Degirmenci V (2019) ZIF-8 Metal Organic Framework for the Conversion of Glucose to Fructose and 5-Hydroxymethyl Furfural. Catalysts (Basel, Switzerland) 9(10): 812.

73. Zheng B, Wang LL, Du L, Pan Y, Lai Z, et al. (2016). Diffusion as a function of guest molecule length and functionalization in flexible metal-organic frameworks. Materials Horizons 3(4): 355-361.

74. Shi Y, Liu G, Jin R, Xu H, Wang Q, et al. (2019) Carbon materials from melamine sponges for supercapacitors and lithium battery electrode materials: A review. Carbon Energy 1(2): 253-275.

75. Zhu H, Chen D, An W, Li N, Xu Q et al. (2015) A robust and cost-effective superhydrophobic graphene foam for efficient oil and organic solvent recovery. Small 11(39): 5222-5229.
76. Saha P, Dashairya L (2018) Reduced graphene oxide modified melamine formaldehyde (rGO@MF) superhydrophobic sponge for efficient oilwater separation. Journal of Porous Materials 25(5): 1475-1488.

77. Anju M, Renuka NK (2020) Magnetically actuated graphene coated polyurethane foam as potential sorbent for oils and organics. Arabian Journal of Chemistry 13(1): 1752-1762.

78. Qiu L, Zhang R, Zhang Y, Li C, Zhang Q, et al. (2018) Superhydrophobic, mechanically flexible and recyclable reduced graphene oxide wrapped sponge for highly efficient oil/water separation. Frontiers of Chemical Science and Engineering 12: 390-399.

79. Zhang Z, Liu H, Qiao W (2020) Reduced graphene-based superhydrophobic sponges modified by hexadecyltrimethoxysilane for oil adsorption. Colloids and Surfaces A: Physicochemical and Engineering Aspects 589: 124433.

80. Fang Y, Huang Q, Liu P, Shi J, Xu G (2018) A facile dip-coating method for the preparation of separable MoS2 sponges and their high-efficient adsorption behaviors of Rhodamine B. Inorganic Chemical Frontiers 5(4): 827-834.

81. Yao Q, Zhao P, Li R, Li C, Luo Y, et al. (2016) Fabrication of recyclable carbonized asphalt-melamine sponges with high oil-absorption capability. Journal of Chemical Technology \& Biotechnology 92(6): 1415-1420.

82. Abe J, Kobayashi Y, Kawase K, Tenjimbayashi M, Shiratori S (2018) Facile synthesis of a high electrical and ion conductivity junction-less 3D carbon sponge electrode for self-standing lithium ion battery anode. RSC Advances 8: 6390-6396.

83. Zhao J, Guo Q Wang X, Xie H, Chen Y (2016) Recycle and reusable melamine sponge coated by graphene for highly efficient oil-absorption. Colloids and Surfaces A: Physicochemical and Engineering Aspects 488: 93-99.

84. Stolz A, Le Floch S, Reinert L, Ramos SMM, Tuaillon Combes J, et al. (2016) Melamine-derived carbon sponges for oil-water separation. Carbon 107: 198-208.

85. Zhao P, Yao Q Zhou G, Yan X, Li S, et al. (2019) Green preparation of nonflammable carbonized asphalt-melamine sponges as recyclable oil absorbents. Materials Chemistry and Physics 226: 235-243.

86. Hong P, Liu Z, Gao Y, Chen Y, Zhuang M, et al. (2019) Fabricated of Superhydrophobic Silanized Melamine Sponge with Photochromic Properties for Efficiency Oil/Water Separation. Designing and Manufacturing of Stimuli-Responsive Polymeric Materials.

87. Rao WH, Xu HX, Xu YJ, Qi M, Liao W, et al. (2018) Persistently flameretardant flexible polyurethane foams by a novel phosphorus-containing polyol. Chemical Engineering Journal 343: 198-206.

88. Shuai Q, Yang X, Luo Y, Tang H, Luo X, et al. (2015) A superhydrophobic poly(dimethylsiloxane) $-\mathrm{TiO}_{2}$ coated polyurethane sponge for selective absorption of oil from water. Materials Chemistry and Physics 162: 9499.

89. Vintu M, Unnikrishnan G (2019) Indolocarbazole based polymer coated super adsorbent polyurethane sponges for oil/organic solvent removal. Journal of Environmental Management 248.

90. Yan T, Chen X, Zhang T, Yu J, Jiang X, et al. (2018) A magnetic pH-induced textile fabric with switchable wettability for intelligent oil/water separation. Chemical Engineering Journal 347: 52-63.

91. Seeharaj P, Pasupong P, Detsri E, Damrongsak P (2017) Superhydrophobilization of $\mathrm{SiO}_{2}$ surface with two alkylsilanes for an application in oil/water separation. Journal of Materials Science 53(7): 4828-4839.

92. Zhu T, Li S, Huang J, Mihailiasa M, Lai Y (2017) Rational design of multilayered superhydrophobic coating on cotton fabrics for UV shielding, self-cleaning and oil-water separation. Materials \& Design 134(2017): 342-351.

93. Cao Y, Zhang W, Li B, Wang F, Feng Y, et al. (2019) Mussel-inspired Ag nanoparticles anchored sponge for oil/water separation and 
contaminants catalytic reduction. Separation and Purification Technology 225: 18-23.

94. Zheng L, Su X, Lai X, Chen W, Li H, et al. (2019) Conductive superhydrophobic cotton fabrics via layer-by-layer assembly of carbon nanotubes for oil-water separation and human motion detection. Materials Letters 253: 230-233.

95. Xia C, Li Y, Fei T, Gong W (2018) Facile one-pot synthesis of superhydrophobic reduced graphene oxide-coated polyurethane sponge at the presence of ethanol for oil-water separation. Chemical Engineering Journal 345: 648-658.

96. Liu C, Fang Y, Miao X, Pei Y, Yan Y, et al. (2019) Facile fabrication of superhydrophobic polyurethane sponge towards oil-water separation with exceptional flame-retardant performance. Separation and Purification Technology 229: 115801.

97. Panda A, Varshney P, Mohapatra SS, Kumar A (2018) Development of liquid repellent coating on cotton fabric by simple binary silanization with excellent self-cleaning and oil-water separation properties. Carbohydrate Polymers 181: 1052-1060.

98. Xiong S, Zhong Z, Wang Y (2017) Direct silanization of polyurethane foams for efficient selective absorption of oil from water. AIChE Journal 63(6): 2232-2240.

99. Lu X, Cui Z, Wei W, Xie J, Jiang L, et al. (2016) Constructing polyurethane sponge modified with silica/graphene oxide nanohybrids as a ternary sorbent. Chemical Engineering Journal 284: 478-486.

100. Qiang F, Hu LL, Gong LX, Zhao L, Li SN, et al. (2018) Facile synthesis of superhydrophobic, electrically conductive and mechanically flexible functionalized graphene nanoribbon/polyurethane sponge for efficient oil/water separation at static and dynamic states. Chemical Engineering Journal 334: 2154-2166.

101. Meng H, Yan T, Yu J, Jiao F (2018) Superhydrophobic and superlipophilic functionalized graphene oxide/polyurethane sponge applied for oil/ water separation. Chinese Journal of Chemical Engineering 26(5): 957-963.

102. Li ZT, Lin B, Jiang LW, Lin EC, Chen J, et al. (2018) Effective preparation of magnetic superhydrophobic $\mathrm{Fe}_{3} \mathrm{O}_{4} / \mathrm{PU}$ sponge for oil-water separation. Applied Surface Science 427: 56-64.

103. Baig N, Alghunaimi FI, Dossary HS, Saleh TA (2019) Superhydrophobic and superoleophilic carbon nanofiber grafted polyurethane for oilwater separation. Process Safety and Environmental Protection 123 327-334.

104. Yu T, Halouane F, Mathias D, Barras A, Wang Z, et al. (2020) Preparation of magnetic, superhydrophobic/superoleophilic polyurethane sponge: Separation of oil/water mixture and demulsification. Chemical Engineering Journal 384

ISSN: 2574-1241

DOI: 10.26717/BJSTR.2020.25.004251

Maria Anna Gatou. Biomed J Sci \& Tech Res (C) This work is licensed under Creative

Submission Link: https://biomedres.us/submit-manuscript.php
105. Wu L, Li L, Li B, Zhang J, Wang A (2015) Magnetic, durable, and superhydrophobic polyurethane@ $\mathrm{Fe}_{3} \mathrm{O}_{4} @ \mathrm{SiO}_{2} @$ fluoropolymer sponges for selective oil absorption and oil/water separation. ACS Applied Materials and Interfaces 7(8): 4936-4946.

106. Rahmani Z, Samadi MT, Kazemi A, Rashidi AM, Rahmani AR (2017) Nanoporous graphene and graphene oxide-coated polyurethane sponge as a highly efficient, superhydrophobic, and reusable oil spill absorbent. Journal of Environmental Chemical Engineering 5(5): 5025-5032.

107. Darband Gh B, Aliofkhazraei M, Khorsand S, Sokhanvar S, Kaboli A (2020) Science and Engineering of Superhydrophobic Surfaces: Review of Corrosion Resistance, Chemical and Mechanical Stability. Arabian Journal of Chemistry 13(1): 1763-1802.

108. Wang H, Wang E, Liu Z, Gao D, Yuan R, et al. (2015) A novel carbon nanotubes reinforced superhydrophobic and superoleophilic polyurethane sponge for selective oil-water separation through a chemical fabrication. Journal of Materials Chemistry A 3(1): 266-273.

109. Zhang T, Xiao C, Zhao J, Cheng J, Chen K, et al. (2019a) Graphene-Coated Poly (ethylene terephthalate) Nonwoven Hollow Tube for Continuous and Highly Effective Oil Collection from the Water Surface. ACS omega 4(4): 7237-7245.

110. Xu Y, Yang H, Zang D, Zhou Y, Liu F, et al. (2018) Preparation of a new superhydrophobic/superoleophilic corn straw fiber used as an oil absorbent for selective absorption of oil from water. Bioresources and Bioprocessing 5: 8.

111. Zhou S, Hao G, Zhou X, Jiang W, Wang T, et al. (2016) One-pot synthesis of robust superhydrophobic, functionalized graphene/polyurethane sponge for effective continuous oil-water separation. Chemical Engineering Journal 302: 155-162.

112. Li M, Xu X, Zhang L (2020) Fabricated superhydrophobic threedimensional rambutan-like- $\beta-\mathrm{NiOOH@sponge} \mathrm{skeletons} \mathrm{for}$ multitasking oil-water separation. Journal of Industrial and Engineering Chemistry.

113. Zhao P, Wang L, Ren R, Han L, Bi F, et al. (2018) Facile fabrication of asphaltene-derived graphene-polyurethane sponges for efficient and selective oil-water separation. Journal of Dispersion Science and Technology 39(7): 977-981.

114. Tran V HT, Lee BK (2017) Novel fabrication of a robust superhydrophobic PU@ZnO@ $\mathrm{Fe}_{3} \mathrm{O}_{4} @ S A$ sponge and its application in oil-water separations. Scientific Reports 7(1): 1-12.

115. Zhao S, Yin L, Zhou Q, Liu C, Zhou K (2020) In situ self-assembly of zeolitic imidazolate frameworks on the surface of flexible polyurethane foam: towards for highly efficient oil spill cleanup and fire safety. Applied Surface Science.

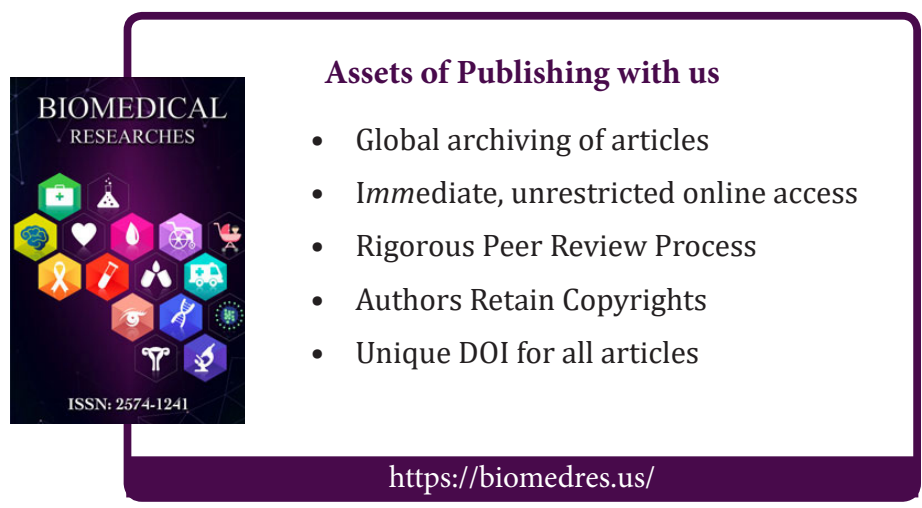

Copyright@ Maria Anna Gatou | Biomed J Sci \& Tech Res | BJSTR. MS.ID.004251. 